\title{
Yaban hayvanlarında antikoagülan rodentisitler ile zehirlenmeler
}

\author{
Orhan Tokur ${ }^{* *}$ (), Abdurrahman Aksoy ${ }^{2}$ (두 \\ 1,2 Ondokuz Mayıs Üniversitesi, Veteriner Fakültesi, Veterinerlik Farmakoloji ve Toksikolojisi Anabilim Dalı, Samsun, TÜRKIYE
}

Geliş Tarihi / Received: 22.02.2021, Kabul Tarihi / Accepted: 14.04.2021

\begin{abstract}
Özet: Antikoagülan rodentisitler kemirici mücadelesinde sık kullanılmaktadırlar. Tuzak yem formunda uygulanan bu maddeleri kedi, köpek gibi evcil hayvanlar ya da serçe, güvercin gibi kuşlar kazara tüketerek zehirlenebilirler. Bu durum primer (birincil) zehirlenme olarak isimlendirilir. Baykuş, tilki, çakal gibi avcı yaban hayvanları ise genellikle kemiricileri avlayarak beslenir ve tuzak yemlere ilgi göstermezler. Tuzak yemi tüketen kemiriciler anormal davranışlar sergiler; kaçış dürtüsü ve hareket kabiliyeti azalarak genellikle birkaç gün içerisinde ölürler. Böylece avcı hayvanlar tarafından kolaylıkla yakalanabilirler. Ancak, kemiricinin vücudunda biriken antikoagülan rodentisitler avcı canlının da zehirlenmesine sebep olabilmektedir. Bu durum ise sekonder (ikincil) zehirlenme olarak isimlendirilir. Bu derlemede, hayvanlarda antikoagülan rodentisit zehirlenmeleri ile ilgili literatürde bildirilmiş veriler değerlendirilerek antikoagülan rodentisit kullanımından kaynaklanabilecek risk faktörlerini, özellikle yaban hayatı açısından aktarmak amaçlanmıştır. Değerlendirilen birçok çalışmada, Amerika, Avrupa ve Avustralya'nın çeşitli bölgelerinde yaşayan evcil ve yaban hayvanlarında hem primer hem de sekonder antikoagülan rodentisit zehirlenmesi bildirilmiş; ülkemizde ise yaban hayvanlarında antikoagülan rodentisit zehirlenmelerinin araştırıldığı herhangi bir çalışmaya rastlanmamıştır.
\end{abstract}

Anahtar kelimeler: Antikoagülan rodentisitler, yaban hayvanları, zehirlenme

\section{Anticoagulant rodenticide poisoning in wild animals}

\begin{abstract}
Anticoagulant rodenticides are often used in rodent control. Pets such as cats, dogs, or birds such as sparrows and pigeons can be poisoned accidentally by ingesting rodenticide bait, which is regarded as primary poisoning. Wild animals such as owls, foxes, jackals, on the other hand, usually hunt rodents and have no interest in bait. When a rodent consumes an anticoagulant rodenticide bait, it exhibits abnormal behaviors such as movement disorders, reduced flight response and usually dies within a few days. As a result, predators can easily hunt the poisoned rodents. However, rodenticides that already have accumulated in the prey's body may affect the predator, leading to secondary poisoning. Secondary poisoning occurs more frequently, especially in areas where human settlement is close to the wildlife. In this review, we evaluated the published data of rodenticide poisoning in animals and showed the risks of anticoagulant rodenticides, particularly in the case of wildlife. Many studies have reported both primary and secondary rodenticide poisoning in domestic and wild animal species in many parts of Europe, America, and Australia. There is, however, no report on rodenticide poisoning in wild animals in Turkey.
\end{abstract}

Keywords: Anticoagulant rodenticides, poisoning, wild animals

\section{Giriş}

Kemirici mücadelesinde kullanılan kapan, yapışkan tuzak gibi fiziksel araçlar kısıtlı bölgelerde etkili olurken, fare ve sıçanların yoğun olarak bulunduğu kentsel ve kırsal bölgelerde, kemirici kontrolünün etkin bir şekilde sağlanabilmesi amacıyla rodentisitler kullanılmaktadır. Nörotoksik etki gösteren striknin ve brometalin, hayati organlarda kalsiyum mineralizasyonuna yol açan kolekalsiferol, vücut içerisinde zehirli fosfin gazı oluşumuna neden olan çinko fosfür gibi birçok madde genellikle tuzak yemlere katılarak rodentisit olarak kullanılmaktadır (Gupta 2018). Kemiricilerin yaşadığı bölgelere bırakılan tuzak yemlerden, bölgede yaşayan kedi, köpek, yaban hayvanları ve kuşlar gibi hedef dışı türler de etkilenerek zehirlenebilir. Perakut zehirliliği çok yüksek olan bu maddelerin spesifik antidotu bulunmamakta ve kazara gerçekleşen zehirlenmeler genellikle ölümle sonuçlanmaktadır (Buckle ve Eason 2015). Bir diğer rodentisit sınıfı olan antikoagülan rodentisitler (AR) ise Vitamin K epoksit redüktaz enzimini inhibe edip kan pıhtılaşma mekanizmasını bozar ve kemiricilerde iç kanamaya yol açarak ölüme sebep olurlar. Ölüm, maruz kalınan AR miktarına bağlı olmakla birlikte genellikle birkaç gün içerisinde meydana gelir (Murphy 2018). Rodentisit olarak kullanılan bazı maddeler Tablo 1.'de gösterilmiştir. 
Tablo 1. Rodentisit olarak kullanılan bazı maddeler.

\begin{tabular}{ll}
\hline Antikogülan Rodentisitler & Diğer rodentisitler \\
\hline Varfarin & Striknin \\
\hline Bromadiolon & Brometalin \\
Brodifakoum & Kolekalsiferol \\
Koumatetralil & Sodyum floroasetat \\
Difenakoum & Alfa-naftil tiyoüre \\
Difasinon & Çinko fosfür \\
\hline Klorofasinon & \\
\hline
\end{tabular}

Kemiriciler, neofobik karakterde canlılardır. Farklı koku ve tatlara sahip besinlere (özellikle tuzak yemler) şüpheyle yaklaşır ve reddederek tüketmeyebilirler (Grau-Perales ve ark. 2019). Tuzak yem uygulaması yapılan bölgelerde sağ kalan kemiricilerin, daha sonra aynı yemi reddederek tekrarlayan uygulamadan etkilenmedikleri gözlenmiştir. Bu tip durumlar özellikle striknin gibi perakut zehirliliği yüksek rodentisitler kullanıldığında daha sık ortaya çıkmaktadır. AR'ler ise tuzak yem alımını takiben genellikle uzun bir zaman diliminde (4 ila 10 gün içerisinde) etkilerini göstermeye başlarlar. Bu nedenle, kemirici canlı tükettiği tuzak yem ile yaşadığı semptomlar veya zehirlenerek ölen diğer kemiriciler ara- sında ilişki kuramaz ve ölene kadar yemi tüketmeye devam eder. Dolayısıyla AR içeren tuzak yemlerde yem reddi durumu ile nadiren karşılaşılmaktadır (Barnett 1988; Macdonald ve ark. 2015). Ayrıca, kazara gerçekleşen AR zehirlenmelerinde spesifik antidot olan vitamin $\mathrm{K}_{1}$ kullanılarak tedavi gerçekleştirilebilir. Belirtilen nedenlerle AR'ler diğer rodentisitlere oranla çok daha sık tercih edilmektedir (Eisemann ve ark. 2018).

\section{Antikoagülan rodentisitler}

Varfarin 1948 yılında AR olarak kullanılmaya başlandıktan (Hayes 1950) kısa bir süre sonra varfarin'e karşı kemiricilerde direnç geliştiği tespit edilmiştir (Boyle 1960). Bunu takiben, varfarinle yapısal olarak benzeşen klorofasinon, difasinon ve koumatetralil gibi rodentisitlere karşı direnç gelişimi birçok araştırmacı tarafından tespit edilmiştir (Greaves ve Rennison 1973; Rennison ve Dubock 1978; Martin ve ark. 1979; Buckle 2013). Birinci nesil AR'ler olarak gruplandırılan bu maddelere karşı gelişen direnç nedeniyle sonraki yıllarda daha güçlü ve etkili bileşikler sentezlenerek 2. nesil AR'ler olarak adlandırılmıştır (Buckle 2013; Mooney ve ark. 2018). Bazı 1. ve 2. nesil AR'ler Tablo 2.'de gösterilmiştir.

Tablo 2. Bazı 1. ve 2. nesil antikoagülan rodentisitler ve kimyasal formülleri.

\begin{tabular}{llll}
\hline 1. Nesil AR & Kimyasal Formülü & 2. Nesil AR & Kimyasal Formülü \\
\hline Varfarin & $\mathrm{C}_{19} \mathrm{H}_{16} \mathrm{O}_{4}$ & Bromadiolon & $\mathrm{C}_{30} \mathrm{H}_{23} \mathrm{BrO}_{4}$ \\
Klorofasinon & $\mathrm{C}_{23} \mathrm{H}_{15} \mathrm{ClO}_{3}$ & Brodifakoum & $\mathrm{C}_{31} \mathrm{H}_{23} \mathrm{BrO}_{3}$ \\
Difasinon & $\mathrm{C}_{23} \mathrm{H}_{16} \mathrm{O}_{3}$ & Difenakoum & $\mathrm{C}_{31} \mathrm{H}_{24} \mathrm{O}_{3}$ \\
Koumatetralil & $\mathrm{C}_{19} \mathrm{H}_{16} \mathrm{O}_{3}$ & Difethialon & $\mathrm{C}_{31} \mathrm{H}_{23} \mathrm{BrO}_{2} \mathrm{~S}$ \\
Koumafuril & $\mathrm{C}_{17} \mathrm{H}_{14} \mathrm{O}_{5}$ & Flokoumafen & $\mathrm{C}_{33} \mathrm{H}_{25} \mathrm{~F}_{3} \mathrm{O}_{4}$ \\
\hline
\end{tabular}

İkinci nesil AR'ler oldukça lipofilik bileşiklerdir ve biyolojik yarılanma ömürleri uzundur. Birinci nesil bileşiklere oranla karaciğerde daha yoğun birikim gösterir ve enterohepatik dolaşıma girerler. Ayrıca, 2. nesil bileşikler vitamin $\mathrm{K}$ epoksit redüktaz enzimine daha fazla affinite gösterirler ve bu nedenle etkileri daha güçlüdür (Watt ve ark. 2005). Örneğin brodifakoum, 2. nesil AR'ler içerisinde etki gücü en yüksek bileşik olup, varfarin'den 40-200 kat daha etkilidir (King ve Tran 2015). Kemiricilerin ölümcül doza maruz kalması için 1. nesil AR içeren tuzak yemlerle birkaç kez beslenmesi gerekirken, 2. nesil AR içeren tuzak yemden bir kez tüketmesi yeterli olabilmektedir (Watt ve ark. 2005). Belirtilen üstünlükleri nedeniyle 2. nesil $A R^{\prime}$ ler süper varfarin olarak adlandırılmış fakat kullanılmaya başlandıktan bir süre sonra bu bileşiklere karşı da direnç tespit edilmiştir (Lund 1984; Gill ve ark. 1992; Blažić ve ark. 2018). Süper varfarinler güçlü etkileriyle kemirici mücadelesindeki başarıyı artırmış; ancak aynı zamanda hedef dışı zehirlenmelerin daha tehlikeli hale gelmesine neden olmuştur.

Bu derlemenin amacl, hayvanlarda gerçekleşen antikoagülan rodentisit zehirlenme vakalarının ve literatür verilerinin incelenerek, antikoagülan rodentisit zehirlenmeleri ile ilgili risk faktörlerini özellikle yaban hayvanları açısından ortaya koymaktır.

\section{Antikoagülan rodentisitlerle zehirlenmeler}

Hedef dışı bir canlının AR içeren tuzak yemi tüketmesi primer zehirlenme olarak adlandırılır. Tuzak yemi tüketen bir canlının (kemirici, kuş, böcek vb.) başka bir canlı tarafından avlanması/yenmesi durumunda oluşan zehirlenme ise sekonder zehirlenme 
olarak adlandırılır. Sekonder zehirlenmeler özellikle yaban hayvanları açısından önem arz etmektedir (Sánchez-Barbudo ve ark. 2012). Ayrıca, böcekçil canlıların AR ile kontamine böcekleri tüketmesi ve avcı canlıların da böcekle beslenen canlıları avlamasi/yemesi durumu tersiyer zehirlenme olarak adlandirilır (Brakes ve Smith 2005).

\section{Antikoagülan rodentisitlerle primer zehirlenmeler}

Insanlarda rodentisit zehirlenmeleri kazara ya da suistimal (intihar) amaçlı gerçekleşmektedir. Tarım sektöründe çalışan işçilerin ya da pestisit uygulaması yapan personelin kazara zehirlendiği, yetişkinlerde ise intihar amaçlı rodentisit kullanımının daha yaygın olduğu bildirilmiştir (Walker ve Beach 2002; Altay ve ark. 2012; Altıparmak ve ark. 2016; Ozturk ve Ugras 2018). Ng ve ark. (2018), 4 yıllık süreçte inceledikleri 41 rodentisit zehirlenme vakasının 30'unun; Xiang ve ark. (2014), 2 yıllık süreçte gerçekleşen 24 vakadan 5'inin intihar amaciyla gerçekleştiğini bildirmiştir. Ayrıca, koruyucu ekipman kullanmadan rodentisit uygulaması yapan işçilerde, tekrarlayan dermal maruziyet sonucu zehirlenme meydana geldiği tespit edilmiştir (Svendsen ve ark. 2002; Bahadır ve ark. 2015; Özdemir ve ark. 2016). Rodentisit zehirlenme vakalarının birçoğunda 2. nesil AR'ler tespit edilmektedir. Yu ve ark. (2013), 20 adet zehirlenme vakasında 12'sinde bromadiolon, 8'inde brodifakoum tespit ederken $\mathrm{Ng}$ ve ark. (2018), 41 vakanın 31 'inde bromadiolon tespit edildiğini aktarmışlardır.

Insanlarda meydana gelen AR zehirlenmelerinde en fazla risk altındaki grup çocuklardır. Özellikle 1-4 yaş grubundaki çocuklar, rodentisitlere kazara maruz kalabilmektedir. Fransa'da gerçekleştirilen bir çalışmada, 4 yıllık süreçte 280 adet AR zehirlenme vakası tespit edilirken bunun \%41'inin 1-4 yaş arası çocuklarda gerçekleştiği bildirilmiştir (Berny ve ark. 2010). Türkiye'de bir tıp fakültesi çocuk acil servisine, 14 aylık süre zarfında zehirlenme şüphesiyle başvuran 491 hastadan 14'ünün rodentisit zehirlenmesi yönünden pozitif olduğu tespit edilmiştir (Kondolot ve ark. 2009). Pestisit zehirlenmeleri ile ilgili retrospektif bir çalışmada zehirlenme vakalarının $1 / 3^{\prime}$ ünün 1-4 yaş arası çocuklarda meydana geldiği ve toplam 709 vakadan 53'ünün AR'ler nedeniyle gerçekleştiği belirtilmiştir (Caldas ve ark. 2008). AR zehirlenmelerinin araştırıldığı başka bir çalışmada toplam vakaların \%70'den fazlasının 5 yaşından küçük çocuklarda gerçekleştiği ortaya konulmuştur (Huntington ve ark. 2016). Çocuklarda kazara oluşan zehirlenmeler genellikle tek sefer ve az miktarda AR alımı sonucu gerçekleştiği için klinik belirtiler hafif olarak gözlen- mekte ve çoğu zaman tedaviye gerek kalmaksızın ve bazen de profilaktik $\mathrm{K}$ vitamini uygulaması ile tedavi edilebilmektedir. Shepherd ve ark. (2002), bromadioIon'a maruz kalmış 6 yaş ve altı 10.762 çocukta, ölüm ya da herhangi bir ciddi klinik belirti gözlenmediğini belirtmiştir. Ancak, bazı AR'ler fetal yolla yavruya geçebilmekte ve bu durum hamilelik esnasında oluşabilecek zehirlenmeler konusunda endişe uyandırmaktadır. Morgan (2006), koumatetralil'in fetal yolla yavruya geçerek embriyotoksik ve teratojenik etkilere yol açıı̆ını tespit etmiştir. AR'ye maruz kalmış hamile bir kadının kanında $126 \mathrm{ng} \mathrm{mL}^{-1}$; doğumun hemen ardından yeni doğan çocuğunun kanında ise $94 \mathrm{ng} \mathrm{mL}^{-1}$ bromadiolon saptanmış; şiddetli beyin kanaması geçiren çocuğun kurtarılamadığı bildirilmiştir (Ma ve ark. 2017). Kazara gerçekleşen zehirlenmeleri engellemek için tuzak yem istasyonlarının yapısının değiş̧irilmesi, çocukların ulaşamayacağ yerlerde konumlandırılması, bazı ülkelerde ise satışının kısıtlanması gibi yöntemlere başvurulmuştur. 1988 yılından itibaren tuzak yemlere katılarak kullanılan denatonyum benzoat (acı tat verici madde) kemiriciler tarafından tespit edilemezken insanlar tarafından acı olarak algılanıp oral maruziyet riskini oldukça düşürmektedir. Bu madde toksik olmamasının yanında rodentisit etkisini de engellememektedir (Kaukeinen ve Buckle 1992; Rattner ve ark. 2014; King ve Tran 2015).

Tuzak yemler, düşük $A R$ konsantrasyonlarıyla $(\% 0,002-\% 0,005)$ ve denatonyum benzoat ile hazırlanmakta; tuzak yem istasyonları ise genellikle 50100 gram arası bloklar içermektedir (Johnston ve ark. 2005). AR'ler içerisinde en zehirli bileşik olarak tanımlanan brodifakoum'un \%50 ölümcül doz $\left(\mathrm{ÖD}_{50}\right)$ değeri genel olarak köpeklerde $3,5 \mathrm{mg} \mathrm{kg}^{-1}$, kedilerde ise $25 \mathrm{mg} \mathrm{kg}^{-1}$ olarak belirtilmektedir (Kopanke ve ark. 2018). Kedi ve köpekler tuzak yemleri kazara yeseler dahi acı tat nedeniyle tüm bloğu tüketmez ve genellikle ölümcül olmayan miktarda rodentisite maruz kalırlar. Bu nedenle evcil hayvanlarda primer AR zehirlenmelerine nadiren rastlanmaktadır. Ancak, uygulama esnasında yapılan hatalar nedeniyle hedef dışı hayvanlar daha fazla rodentisite erişebilir ve primer olarak ölümcül dozlara maruz kalabilirler. Ayrıca, AR'ler karaciğerde yoğun olarak akümüle olabildikleri için tekrarlayan maruziyet sonucu hedef dışı canlının vücudunda ölüme neden olabilecek miktarda AR birikebilir (Godfrey 1985; Stone ve ark. 1999). Primer AR zehirlenmeleri başta sokak hayvanları olmak üzere kedi ve köpeklerde (Berny ve ark. 2010; Kırbaş ve ark. 2012; Griggs ve ark. 2016; Thomer ve Santoro 2018) bazen de serçe, güvercin gibi avcı olmayan kuşlar ya da yaban hayvanların- 
da bildirilmektedir. Sarabia ve ark. (2008), klorofasinon içeren buğday tanelerini tüketen çok sayıda güvercinin öldüğünü belirleyerek, nekropsi sonucu güvercinlerin vücudunda yoğun subkutanöz kanamalar saptamıs ve kursaklarının zehirli tanelerle dolu olduğunu bildirmiştir. Tuzak yemlere maruziyet ve zehirlenme, kış mevsimi gibi yem kaynaklarının azaldığı zamanlarda daha sık şekillenmektedir. Tuzak yemlerin açık alandan ziyade kapalı kutularda sadece kemiricilerin erişebileceği şekilde dizayn edilmesi primer zehirlenme riskini azaltsa da özellikle kuşlar tuzak yem istasyonlarına kolaylıkla erişebilmektedir. Serçe, güvercin gibi küçük yapıdaki kuşlar yem istasyonlarına direkt girebilir veya uzun gagalı kuşlar dışardan yeme erişebilirler. Kuşlar aynı zamanda istasyon etrafında bulunan ve zehirli yemi tüketerek kontamine olmuş böceklerle de beslenebilirler (Vyas 2017). Ancak, sansar ya da baykuş gibi tamamen karnivor beslenme şekline sahip avcı türler tuzak yemlere genellikle ilgi göstermezler. Bu nedenle AR'lere primer olarak maruz kalma ihtimalleri oldukça zayıftır (Shore ve ark. 1999). Çiftlik hayvanlarında AR maruziyetine nadiren rastlanmasına rağmen ilgili bileşiklerin hayvansal ürünlere geçebildiğinin gösterilmesi, halk sağlığı açısından önem arz etmektedir. Kammerer ve ark. (1998), oral yolla varfarin uyguladıkları tavuklarda yumurta ile varfarin ekskresyonunun 14. güne kadar devam ettiğini; Vries ve Schmitz-Kummer (1994), fenprokumon'un sütle atıldığını bildirmiş̧tir. Bazı AR aktif maddelerinin rumende yıkımlanmaması ve oral biyoyararlanım değerlerinin yüksek olması (Berny ve ark. 2006) bu maddelerin hayvansal ürünlerde kalıntı olarak bulunabileceğine işaret etmektedir. Buna ek olarak Pitt ve ark. (2011), pişirme işleminin difasinon üzerine çok az etkisi olduğunu, ilgili maddenin en çok karaciğerde saptanırken ete de geçebileceğini belirtmişlerdir. Ancak, literatür araştırmasında hayvansal gıdalar aracılığıyla oluşan herhangi bir AR zehirlenmesi bildirimine rastlanmamıştır.

\section{Antikoagülan rodentisitlerle sekonder ve tersiyer zehirlenmeler}

Yaban hayatı açısından büyük risk teşkil eden sekonder zehirlenmeler, kemiricileri avlayan tilki, çakal, gelincik, vaşak gibi memeli türlerinin yanı sıra baykuş, şahin, kartal, atmaca gibi avcı kuş türlerini etkilemektedir. Özellikle kış aylarında besin sıkıntısı yaşayan gelincikler, gıda ihtiyaçlarının büyük kısmını fare ve sıçanları avlayarak karşılamaktadır (Shore ve ark. 1999; Zielinski ve ark. 2020). Kemiriciler ise yaz aylarında rahatıkla besin bulabilirken, kış aylarında yeterince besin bulamayarak tuzak yemlere daha çok ilgi göstermekte ve böylece soğuk mevsimlerde tuzak yemlerin etkisi artmaktadır (Lefebvre ve ark. 2017). Ayrıca, kemiriciler kış mevsiminde soğuktan korunmak için kentsel bölgelerde genel olarak kanalizasyon ve evlerde, kırsal bölgelerde ise çiftliklerde yoğunlaşmaktadır (Feng ve Himsworth 2014). Dolayısıyla insanların yoğun olarak yaşadıkları bölgelerde rodentisit kullanımı özellikle kış aylarında artmaktadır. Kırsal alanlarda yaşayan yaban hayvanlarında AR maruziyetine daha az rastlanırken, kentsel alanlara yakın bölgelerde yaşamını sürdürenlerde zehirlenme sıklığının ve örneklerde tespit edilen AR miktarının arttığı bildirilmiştir (López-Perea ve ark. 2015; Lohr 2018; López-Perea ve ark. 2019). Kemirici popülasyonunun artışı nedeniyle yoğun miktarda $A R$ kullanılmaya başlanan bölgelerde, çevrede yaşayan hedef dışı canlıların primer ya da sekonder olarak AR'lerden etkilenme riskleri artmaktadır (Fourel ve ark. 2018). AR maruziyeti ile ilgili yaban hayvanlarında yapılan bazı tarama çalışmaları, incelenen yaban hayvanları ve numunelerde tespit edilen antikoagülan rodentisit miktarları Tablo 3.'te özetlenmiştir.

Kemiriciler, avcılardan korunmak için tigmotaksi (açık alandan ziyade duvar gibi dikey yüzeylere yakın konumda yürüme) ve nokturnal yaşam gibi davranışlar geliştirmiştir. AR'lere maruz kalan kemiriciler ise açık alanda bulunma, gündüz yuva dışına çıkma, sersemlik gibi çeşitli davranış bozuklukları göstermekte (Cox ve Smith 1992); kaçış dürtülerinin azaldığı ve hareket kabiliyetlerinin düştüğü bildirilmektedir (Brakes ve Smith 2005). Il gili durumlar, avcıların $A R$ 'den etkilenen kemiricileri daha kolay yakalamasına ve dolayısıyla sekonder zehirlenme riskinin artmasına neden olmaktadır. Sekonder zehirlenmeye katkı yapan bir diğer unsur ise özellikle 2. nesil AR'lerin karaciğerde yüksek derecede akümüle olmasıdır. Birinci nesil AR'lerin karaciğerde ortalama yarılanma ömürleri 30-55 gün iken 2. nesil bileşiklerde bu süre 220 güne kadar uzayabilmektedir (Sánchez-Barbudo ve ark. 2012). Kemirgenler, AR'lerin gecikmeli etkileri nedeniyle ölmeleri için yeterli miktardan daha fazla rodentisit tüketebilir ve bu maddeler vücutlarında birikir. AR'lere dirençli bazı kemirgenler ise, normalde ölümcül olabilecek miktardaki AR'lerden etkilenmez ve tuzak yemi tüketmeye devam eder. Böylece, vücutlarında çok daha fazla miktarda $A R$ biriken bu dirençli kemiriciler, avcı canlılar açısından daha büyük risk oluştururlar (Smith ve Shore 2015; Blažić ve ark. 2018). AR maruziyeti sonucu şekillenen davranışsal değişiklikler avcı canlıları da etkilemektedir. Saravanan ve Kanakasabai (2004), peçeli baykuşlara, difetialon içeren yem ile beslenmiş sıçanları yedirerek baykuşları davranış değişikliği yönünden 
incelemiş; subletal dozlarda ele alınmaya kayıtsızlık, sersemlik gibi davranışsal semptomlar belirlemiştir. Ayrıca, baykuşların sıçanları parçaladıkları; ancak genellikle tamamen yemedikleri bildirilmiştir. Benzer bir çalışmada brodifakoum, difenakoum, flokoumafen içeren yemle beslenmiş fareler (her bir fare sadece tek bir AR içeren yemle beslenmiş) peçeli baykuşlara sunularak bu maddelerin toksisiteleri (her bir baykuş tek bir AR'ye maruz kalmış) değerlendirilmiştir. Bu çalışmada da baykuşların fareleri parçala- yarak bir kısmını (özellikle bağırsaklar) yemediği bazen ise fareyi tamamıyla reddederek yemediği gözlenmiştir. Kümülatif olarak brodifakoum $3,3 \mathrm{mg} / \mathrm{kg}$, difenakoum ve flokoumafen 1,9 mg/kg'a doza kadar baykuşların yaşadığı; brodifakoum $5,4 \mathrm{mg} / \mathrm{kg}$, difenakoum 3,7 mg/ $\mathrm{kg}$, flokoumafen $2,2 \mathrm{mg} / \mathrm{kg}$ dozda ise ölüm gerçekleştiği tespit edilmiştir (Gray ve ark. 1994). Ancak, ilgili çalışmada inceleme yapılan baykuş sayısı yetersiz (12 adet) olduğu için kümülatif öldürücü dozlar gerçeği tam olarak yansıtmayabilir.

Tablo 3. Yaban hayvanlarında tespit edilen antikoagülan rodentisit miktarları.

\begin{tabular}{|c|c|c|c|c|c|}
\hline Tür & $\mathbf{N}$ & $\mathbf{N}^{+}{ }_{(A R)}$ & $\mathbf{N}_{(\text {AR })}^{+}>1$ & $\sum$ AR ortalama $(\mu \mathrm{g} / \mathrm{kg})$ & Kaynak \\
\hline Vaşak (Lynx rufus) & 39 & 35 & 27 & $\begin{array}{c}350 \\
(10-890)\end{array}$ & $\begin{array}{l}\text { (Riley ve ark. } \\
\text { 2007) }\end{array}$ \\
\hline Kır Kurdu (Canis latrans) & 5 & 5 & 1 & $\begin{array}{c}340 \\
(90-1200)\end{array}$ & $\begin{array}{c}\text { (Poessel ve ark. } \\
\text { 2015) }\end{array}$ \\
\hline Gelincik (Mustela putorius) & 68 & 54 & 35 & $\begin{array}{c}120 \\
(1-3162)\end{array}$ & $\begin{array}{c}\text { (Sainsbury ve ark. } \\
\text { 2018) }\end{array}$ \\
\hline Kızıl Tilki (Vulpes vulpes) & 311 & 198 & 128 & $\begin{array}{c}? \\
(1-2433)\end{array}$ & $\begin{array}{c}\text { (Geduhn ve ark. } \\
\text { 2015) }\end{array}$ \\
\hline Balıkçıl Sansar (Martes pennanti) & 58 & 46 & $?$ & $\begin{array}{c}? \\
(120-3400)\end{array}$ & $\begin{array}{c}\text { (Gabriel ve ark. } \\
\text { 2012) }\end{array}$ \\
\hline Kaya Sansarı (Martes foina) & 71 & 70 & 65 & $\begin{array}{c}727 \\
(?-2361)\end{array}$ & \multirow{2}{*}{$\begin{array}{c}\text { (Elmeros ve ark. } \\
\text { 2018) }\end{array}$} \\
\hline Gelincik (Mustela putorius) & 69 & 65 & 47 & $\begin{array}{c}242 \\
(?-1466)\end{array}$ & \\
\hline Kakım (Mustela erminea) & 61 & 59 & 50 & \multirow{2}{*}{$\begin{array}{c}? \\
(1-1290)\end{array}$} & \multirow{2}{*}{$\begin{array}{c}\text { (Elmeros ve ark. } \\
\text { 2011) }\end{array}$} \\
\hline Bayağı Gelincik (Mustela nivalis) & 69 & 65 & 48 & & \\
\hline Kızıl Kuyruklu Şahin (Buteo jamaicensis) & 37 & 36 & 29 & \multirow{4}{*}{$\begin{array}{c}118 \\
(10-900)\end{array}$} & \multirow{4}{*}{ (Murray 2011) } \\
\hline Çizgili Baykuş (Strix varia) & 24 & 21 & 10 & & \\
\hline Puhu (Bubo virginianus) & 17 & 17 & 11 & & \\
\hline Eastern Screech Owl* (Megascops asio) & 16 & 16 & 12 & & \\
\hline Southern BooBook* (Ninox boobook) & 73 & 53 & 28 & $\begin{array}{c}310 \\
(?-4002)\end{array}$ & (Lohr 2018) \\
\hline Kızıl Kuyruklu Şahin (Buteo jamaicensis) & 105 & 85 & 16 & \multirow{2}{*}{$\begin{array}{c}100 \\
(10-950)\end{array}$} & \multirow{2}{*}{$\begin{array}{c}\text { (Stansley ve ark. } \\
\text { 2014) }\end{array}$} \\
\hline Puhu (Bubo virginianus) & 22 & 18 & 4 & & \\
\hline Puhu (Bubo virginianus) & 78 & 43 & \multirow{3}{*}{67} & \multirow{3}{*}{$\begin{array}{c}? \\
(1-1120)\end{array}$} & \multirow{3}{*}{$\begin{array}{l}\text { (Albert ve ark. } \\
\text { 2010) }\end{array}$} \\
\hline Çizgili Baykuş (Strix varia) & 25 & 23 & & & \\
\hline Peçeli Baykuş (Tyto alba) & 61 & 48 & & & \\
\hline Bayağı Atmaca (Accipiter nisus) & 14 & 6 & \multirow{5}{*}{38} & \multirow{5}{*}{$\begin{array}{c}139 \\
(0.1-702)\end{array}$} & \multirow{5}{*}{$\begin{array}{c}\text { (Ruiz-Suárez ve } \\
\text { ark. 2014) }\end{array}$} \\
\hline Kulaklı Orman Baykuşu (Asio otus) & 23 & 17 & & & \\
\hline Kızıl Enseli Doğan (Falco pelegrinoides) & 16 & 5 & & & \\
\hline Bayağı Kerkenez (Falco tinnunculus) & 21 & 14 & & & \\
\hline Peçeli Baykuş (Tyto alba) & 21 & 16 & & & \\
\hline Kızıl Çaylak (Milvul milvus) & 114 & 79 & 28 & $\begin{array}{l}155 \\
(?)\end{array}$ & $\begin{array}{c}\text { (Hughes ve ark. } \\
\text { 2013) }\end{array}$ \\
\hline Kızıl Tilki (Vulpes vulpes) & 40 & 32 & 27 & $\begin{array}{c}? \\
(1-192) \\
\end{array}$ & $\begin{array}{c}\text { (Seljetun ve ark. } \\
\text { 2020) }\end{array}$ \\
\hline
\end{tabular}

$\mathbf{N}$ : İncelenen numune sayısı, $\mathbf{N}^{+}$: AR tespit edilen numune sayısı, $\mathbf{N + ( A R ) > 1 : ~ I c ̧ ̧ e r i g ̆ i n d e ~ b i r d e n ~ f a z l a ~ A R ~ b i l e s ̧ i g ̆ i ~ t e s p i t ~ e d i l e n ~ o ̈ r - ~}$ nek sayısı, ¿ARortalama: Numunelerde saptanan ortalama rodentisit konsantrasyonu (minimum ve maksimum konsantrasyonlar) *Türkçe karşılığı bulunamadığı için İngilizce ismi yazılmıştır. 
AR toksisitesi omurgasız canlılar üzerinde daha zayıf olarak şekillenir. Omurgasız canlılar genellikle memeli ve kuşlarda toksik etkiye neden olan AR dozlarından etkilenmezler. Bu durum AR içerikli tuzak yemleri tüketen omurgasızların, böcekçil memeli ve kuş türlerinde sekonder zehirlenmeye aracılık edebilmesine neden olur (Johnston ve ark. 2005; Dowding ve ark. 2010). Spurr ve Drew (1999), AR içeren çeşitli tuzak yemlerin başta Huberia brounii türü karıncalar olmak üzere en az 45 farklı türden omurgasız canlı tarafından tüketildiğini saptamış ve ilgili durumun özellikle böcekçil kuşlar için sekonder zehirlenme riskine işaret ettiğini belirtmiştir. Benzer şekilde Alomar ve ark. (2018), AR tuzak yemlerinin sümüklü böcekler (Deroceras reticulatum) tarafından tüketilerek sümüklü böceklerin kontamine olabildiğini ve bu durumun sivri fare (Sorex araneus), kirpi (Erinaceus europaeus) ve sığırcık (Sturnus vulgaris) gibi sümüklü böceklerle beslenen canlılarda sekonder zehirlenmeye sebep olabileceğini; Booth ve ark. (2003), yer solucanlarının da benzer şekilde sekonder zehirlenmeye aracılık edebileceğini belirtmiştir. Dowding ve ark. (2010), 120 adet kirpi (Erinaceus europaeus) karaciğerinde AR kalıntısını araştırdıkları çalışmada 80 kirpide AR bileşiği tespit etmiş ve pozitif örneklerin 27'sinde birden fazla AR bileşiği bulunduğunu ortaya koyarak böcekçil canlılarda sekonder zehirlenmeye dikkat çekmiştir. Ancak, böcek vücudunda biriken AR miktarının düşük ve atılımının memeli ve kuşlara oranla daha hızlı gerçekleşmesi nedeniyle böceklerin sekonder/tersiyer zehirlenmelere aracılık etme riskleri oldukça düşüktür (Brooke ve ark. 2013).

AR zehirlenmesi uyuşukluk, zayıflık, algı ve hareketin azalması, kanama gibi spesifik olmayan klinik belirtilere sahiptir. Yaban hayatına dair toplanan çoğu örnek daha önceden ölmüş hayvanlardan alındığı için ölüm sebebine işaret edebilecek lezyonlar ve bulgular kesin olarak ayırt edilememektedir. Ayrıca evcil hayvanlardaki öldürücü AR konsantrasyonlarının bilinmesine karşın yaban hayvanlarındaki öldürücü konsantrasyonlar tam olarak tespit edilmemiştir. Bu nedenlerle yaban hayvanlarında tespit edilen AR miktarları ile ölüm sebebi arasında tam bir ilişki kurulamamaktadır (Elmeros ve ark. 2011; Lefebvre ve ark. 2017; Sainsbury ve ark. 2018). Kemirgenleri avlayan baykuş, şahin gibi kuş türleri veya karnivor beslenme şekline sahip gelincik, tilki gibi memelilerin farklı tuzak yemlere ulaşma şansı oldukça düşük ve bu yemleri tüketme isteği zayıftır. Bu bağlamda sekonder zehirlenme tespitini destekleyen bulgulardan biri travmatik hasar olmaksızın gerçekleşen iç kanama iken (Şekil 1.) (Stone ve ark. 1999), ikincisi ve en önemlisi, analiz edilen örneklerde birden fazla AR aktif maddesinin tespit edilmesidir. Christensen ve ark. (2012), 5 farklı yırtıcı ve 6 farklı baykuş türünden olmak üzere toplam 430 adet örneği analiz ederek \%92'sinde AR saptamış; AR saptanan örneklerin ise \%73'ünün birden fazla AR içerdiğini tespit etmiştir. Lohr (2018), 73 adet baykuş karaciğerini analiz ederek \%72,6'sında tek, \%38,4'ünde birden fazla AR tespit etmiş; 7 adet baykuşta ise dış bakıda herhangi bir zehirlenme belirtisi (örn; kanama) gözlemezken disseksiyon esnasında muhtemel AR kaynaklı torasik kavitede kanama, subdermal ve muskular kanamalar, ağız ve gaga çevresinde kanama gözlemlemiştir. Sánchez-Barbudo ve ark. (2012), 2 farklı sürüngen, 18 farklı memeli ve 42 farklı kuş türünden olmak üzere toplam 401 adet evcil hayvan ve yaban hayvanını inceleyerek \%38,7'sinin AR ile kontamine olduğunu; klinik belirtiler, nekropsi ve toksikolojik analizler sonucunda ise \%34,9'unun AR'ler nedeniyle hayatın kaybetmiş olabileceğini bildirmiştir. Albert ve ark. (2010), çeşitli hayvanlardan elde edilen 164 örneğin \%10'unda üç farklı, sadece 1 örnekte ise 4 farklı AR tespit ederken; Elmeros ve ark. (2011), inceledikleri 4 adet kakım ve gelinciğin tamamında brodifakoum, bromadiolon, koumatetralil, difenakoum, flokoumafen olmak üzere 5 farklı AR tespit etmiştir. Yaban hayatında insanla karşılaşma olasılığı düşük olan nadir türlerin de AR'lerden etkilendiği gösterilmiştir. Riley ve ark. (2007), AR zehirlenmesi nedeniyle öldüğünü belirledikleri 2 adet pumanın karaciğerlerinde sırasıyla 1,27 ve $0,51 \mathrm{mg} / \mathrm{kg}$ bromadiolon, 0,57 ve 0,31 $\mathrm{mg} / \mathrm{kg}$ brodifakoum tespit etmişlerdir.

AR'lerin yavrulara aktarımının araştırıldığı bir çalışmada, tarla faresi mücadelesi yapılan kırsal bir bölgede, 40 farklı kerkenez yuvasında bulunan toplam 112 kerkenez yavrusundan alınan kanlar analiz edilerek 19 örnekte bromadiolon tespit edilmiştir. Bromadiolon'a maruz kalmış kerkenez yavrularının vücut ağırlıklarının ise maruz kalmamış olanlara göre \%6,7 oranında daha zayıf olduğu belirlenmiştir (Martínez-Padilla ve ark. 2017). Gabriel ve ark. (2012), AR zehirlenmesi nedeniyle ölen bir anne sansarın, sütü aracılığıyla yavrusuna $A R$ aktarmış olduğunu tespit etmiş; ancak yavruda AR zehirlenmesine ilişkin herhangi bir belirtiye rastlanmadığını bildirmiştir. Salim ve ark. (2015), bromadiolon ya da klorofasinon aktif maddelerine maruz kalan peçeli baykuşların yumurtalarında ilgili maddeleri tespit etmiş ancak bu durumun yumurta kabuğu kalınlığı ve yumurta şeklini etkilemediğini bildirmiştir.

AR'lerin yoğun kullanımı, uzun vadede bölgede yaşayan avcı türlerin sayısını da etkileyebilmektedir. Proulx ve Mackenzie (2012), yoğun ve seyrek ola- 
rak rodentisit uygulanan iki farklı bölgeyi avcı yaban hayvanları sayıları yönünden karşılaştırmış; rodentisit uygulamasının az olduğu bölgedeki porsuk ve tilki sayısını yoğun olan bölgeye oranla sırasıyla 2,2 ve 6,4 kat fazla bulmuştur. Ayrıca, AR'lerin direkt etkileri dışında tuzak yem hazırlanırken kullanılan bazı yardımcı maddeler de yaban hayvanlarına zarar verebilmektedir. Özellikle pelet formundaki tuzak yemlerin hava şartlarına dayanıklılığını artırmak için eklenen parafin, bazı kuşlarda taşlık tıkanmasına (gizzard impaction) sebep olarak ölüme yol açabilmektedir (Blus ve ark. 1985; Vyas 2017).

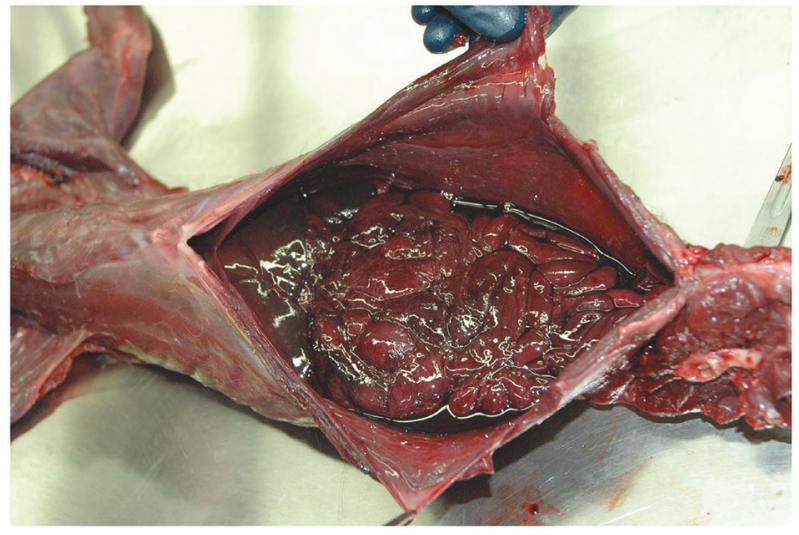

Şekil 1. Ölümcül AR maruziyeti sonucu torasik kavitede yoğun kan birikimi (Gabriel ve ark. 2012).

Yaban hayatında AR maruziyetini belirlemek için yapılabilecek geniş çaplı çalışmalarda, ölü hayvanları bulmak veya incelenecek hayvanların ölmesini beklemek uzun ve yorucu bir çabadır. Bu nedenle tarama çalışmalarında ana örnek olan karaciğer yerine dışkıda bulunan AR'lerin araştırılabileceği ileri sürülmüştür. Ancak, taze dışkı örneklerinin analizi gerçek değerleri yansıtsa da hava koşullarına bağlı olarak AR konsantrasyonunun hızla düştüğü ve üzerinden uzun zaman geçmiş örneklerin gerçek maruziyeti yansıtmadığı belirtilmiştir (Prat-Mairet ve ark. 2017; Fourel ve ark. 2018; Seljetun ve ark. 2018). AR zehirlenmesi tespitine yönelik çalışmalarda karaciğere diğer bir alternatif olarak Newton ve ark. (1994), baykuşların beslenme sonrası regurgitasyon ile çıkardıkları besin artıklarının kullanılabileceğini belirtmişlerdir.

\section{Sonuç}

Tuzak yemlerde bulunan AR konsantrasyonları oldukça düşüktür. Acı tat verici maddeler ise kazara oluşabilecek yem tüketimini sınırlamaktadır. Bu nedenle kedi, köpek gibi evcil hayvanlarda kasıtlı eylemler dışında primer AR zehirlenme insidansı düşüktür. Sekonder zehirlenme bakımından yaban hayvanlarının ölümcül doza maruz kalabilmesi ise AR ile kontamine çok sayıda kemirici tüketmesi ile ancak mümkün olmaktadır. Bu nedenle özellikle yaban hayatında gerçekleşen AR zehirlenmelerinin ölümcül etkilerinden çok davranışsal, reprodüktif ve hormonal bozukluklar ile ilgili çeşitli subletal etkilerinin açığa çıkarılması gerekmektedir. AR zehirlenmesinin kolaylıkla tedavi edilebilir olması, genel olarak insektisit ve herbisit zehirlenmelerine nispeten daha hafif seyretmesi, insan ve evcil hayvanlarda zehirlenme riskini düşüren başlıca etkenler arasında yer almaktadır. Ancak, yaban hayvanları ve dolayısıyla ekosistem açısından özellikle sekonder zehirlenme riski halen yüksektir. Evcil hayvanlar ve insanlarda gerçekleşen zehirlenmelere dair kayıtlar düzenli olarak tutulabilmekte iken yaban hayvanlarında gerçekleşen zehirlenmeler ancak tarama çalışmaları sonucu ortaya çıkmakta, birçok zehirlenme vakası muhtemelen gözden kaçırılmaktadır. Yapılan literatür taraması sonucu, ülkemizde yaban hayvanlarında AR kalıntısı araştırılan bir çalışmaya rastlanmamıştır. Dolayısıyla ülkemizde yaşayan yaban hayvanlarının AR maruziyetinin belirlenmesi ve zehirlenme nedenlerinin ortaya çıkarılabilmesi için çok sayıda çalışmaya intiyaç vardır.

Maddi destek ve çıkar ilişkisi: Çalışmayı maddi olarak destekleyen kişi/kuruluş yoktur ve yazarların herhangi bir çıkara dayalı ilişkisi yoktur.

\section{Kaynaklar}

Albert CA, Wilson LK, Mineau P, Trudeau S, Elliott JE. (2010). Anticoagulant rodenticides in three owl species from western Canada, 1988-2003. Arch Environ Contam Toxicol. 58(2), 451459. doi: https://doi.org/10.1007/s00244-009-9402-z.

Alomar H, Chabert A, Coeurdassier M, Vey D, Berny P. (2018). Accumulation of anticoagulant rodenticides (chlorophacinone, bromadiolone and brodifacoum) in a non-target invertebrate, the slug, Deroceras reticulatum. Sci Total Environ. 610, 576-582. doi: https://doi.org/10.1016/j.scitotenv.2017.08.117.

Altay S, Velibey Y, Cakmak HA, Boz GC, Koca S. (2012). Prolonged coagulopathy related to coumarin rodenticide in a young patient: superwarfarin poisoning: case report-online article. Cardiovasc J Afr. 23(9), 9-11.

Altıparmak B, Uysal Al, Tarakçı E, Sahan L, Demirbilek S. (2016) Rodentisit (fare zehiri) ve etilen glikol (antifriz) ile intihar girişimi. J Anesth. 24(3), 200-203.

Bahadır A, Akca Ö, Bülbül İ, Kahveci R, Özkara A. (2015). Supervarfarinin cilt emilimi sonucu ortaya çıkan INR yüksekliği ve vitamin K eksikliği: Olgu sunumu. Medeniyet Med J. 30(2), 99 101. doi: https://doi.org/10.5222/MMJ.2015.099.

Barnett S. (1988). Exploring, sampling, neophobia, and feeding Prakash I. eds. Rodent pest management. CRC press, Boca Raton. p. 296-317.

Berny P, Velardo J, Pulce C, D'amico A, Kammerer M, Lasseur R (2010). Prevalence of anticoagulant rodenticide poisoning in humans and animals in France and substances involved. Clin 
Toxicol. 48(9), 935-941. doi: https://doi.org/10.3109/1556365 0.2010 .533678 .

Berny PJ, de Oliveira LA, Videmann B, Rossi S. (2006). Assessment of ruminal degradation, oral bioavailability, and toxic effects of anticoagulant rodenticides in sheep. Am J Vet Res. 67(2), 363-371. doi: https://doi.org/10.2460/ajvr.67.2.363.

Blažić T, Jokić G, Götz M, Esther A, Vukša M, Đedović S. (2018). Brodifacoum as a first choice rodenticide for controlling bromadiolone-resistant Mus musculus. J Stored Prod Res. 79, 2933. doi: https://doi.org/10.1016/j.jspr.2018.08.006.

Blus LJ, Henny CJ, Grove RA. (1985). Effects of pelletized anticoagulant rodenticides on California quail. J Wildl Dis. 21(4), 391 395. doi: https://doi.org/10.7589/0090-3558-21.4.391.

Booth L, Fisher P, Heppelthwaite V, Eason C. (2003). Toxicity and residues of brodifacoum in snails and earthworms. DOC Science Internal Series. 143, 5-14.

Boyle CM. (1960). Case of apparent resistance of Rattus norvegicus Berkenhout to anticoagulant poisons. Nature. 188(4749), 517. doi: https://doi.org/10.1038/188517a0.

Brakes C, Smith RH. (2005). Exposure of non-target small mammals to rodenticides: short-term effects, recovery and implications for secondary poisoning. J Appl Ecol. 42(1), 118-128. doi: https://doi.org/10.1111/j.1365-2664.2005.00997.x.

Brooke MdL, Cuthbert R, Harrison G, Gordon C, Taggart M. (2013). Persistence of brodifacoum in cockroach and woodlice: implications for secondary poisoning during rodent eradications. Ecotoxicol Environ Saf. 97, 183-188. doi: https://doi. org/10.1016/j.ecoenv.2013.08.007.

Buckle A. (2013). Anticoagulant resistance in the United Kingdom and a new guideline for the management of resistant infestations of Norway rats (Rattus norvegicus Berk.). Pest Manag Sci. 69(3), 334-341. doi: https://doi.org/10.1002/ps.3309.

Buckle AP, Eason C. (2015). Control methods: chemical. Buckle A, Smith R. eds. Rodent pests and their control. CAB International, United Kingdom. p. 123-154

Caldas ED, Rebelo FM, Heliodoro VO, Magalhães AF, Rebelo RM. (2008). Poisonings with pesticides in the Federal District of Brazil. Clin Toxicol. 46(10), 1058-1063. doi: https://doi. org/10.1080/15563650802530443.

Christensen TK, Lassen P, Elmeros M. (2012). High exposure rates of anticoagulant rodenticides in predatory bird species in intensively managed landscapes in Denmark. Arch Environ Contam Toxicol. 63(3), 437-444. doi: https://doi.org/10.1007/ s00244-012-9771-6.

Cox P, Smith R. (1992). Rodenticide ecotoxicology: pre-lethal effects of anticoagulants on rat behaviour. Proceedings of the Fifteenth Vertebrate Pest Conference, March 3-5, California-USA.

Dowding CV, Shore RF, Worgan A, Baker PJ, Harris S. (2010). Accumulation of anticoagulant rodenticides in a non-target insectivore, the European hedgehog (Erinaceus europaeus). Environmental Pollution. 158(1), 161-166. doi: https://doi.org/10.1016/j.envpol.2009.07.017.

Eisemann JD, Fisher PM, Buckle A, Humphrys S. (2018). An International Perspective on the Regulation of Rodenticides. Van den Brink NW, Elliott JE, Shore RF, Rattner BA eds. Anticoagulant Rodenticides and Wildlife. Springer Inc., p. 287-318.

Elmeros M, Christensen TK, Lassen P. (2011). Concentrations of anticoagulant rodenticides in stoats Mustela erminea and weasels Mustela nivalis from Denmark. Sci Total Environ. 409(12), 2373-2378. doi: https://doi.org/10.1016/j.scitotenv.2011.03.006

Elmeros M, Lassen P, Bossi R, Topping CJ. (2018). Exposure of stone marten (Martes foina) and polecat (Mustela putorius) to anticoagulant rodenticides: Effects of regulatory restrictions of rodenticide use. Sci Total Environ. 612, 1358-1364. doi: https://doi.org/10.1016/j.scitotenv.2017.09.034.

Feng AY, Himsworth CG. (2014). The secret life of the city rat: a review of the ecology of urban Norway and black rats (Rattus norvegicus and Rattus rattus). Urban Ecosyst. 17(1), 149-162. doi: https://doi.org/10.1007/s11252-013-0305-4.

Fourel I, Sage M, Benoit E, Lattard V. (2018). Liver and fecal samples suggest differential exposure of red fox (Vulpes vulpes) to trans-and cis-bromadiolone in areas from France treated with plant protection products. Sci Total Environ. 622, 924929. doi: https://doi.org/10.1016/j.scitotenv.2017.12.053.

Gabriel MW, Woods LW, Poppenga R, Sweitzer RA, Thompson C, Matthews SM, Higley JM, Keller SM, Purcell K, Barrett RH. (2012). Anticoagulant rodenticides on our public and community lands: spatial distribution of exposure and poisoning of a rare forest carnivore. PLoS One. 7(7), e40163. doi: https:// doi.org/10.1371/journal.pone.0040163.

Geduhn A, Jacob J, Schenke D, Keller B, Kleinschmidt S, Esther A. (2015). Relation between intensity of biocide practice and residues of anticoagulant rodenticides in red foxes (Vulpes vulpes). PLoS One. 10(9), e0139191. doi: https://doi. org/10.1371/journal.pone.0139191.

Gill JE, Kerins GM, MacNicoll AD. (1992). Inheritance of low grade brodifacoum resistance in the Norway rat. J Wildl Manag. 809-816. doi: https://doi.org/10.2307/3809478.

Godfrey M. (1985). Non-target and secondary poisoning hazards of "second generation" anticoagulants. Acta Zool Fenn. 173, 209-212.

Grau-Perales A, Levy E, Fenton A, Gallo M. (2019). Dorsal hippocampal damage disrupts the auditory context-dependent attenuation of taste neophobia in mice. Neurobiol Learn Mem. 157, 121-127. doi: https://doi.org/10.1016/j.nlm.2018.12.009.

Gray A, Eadsforth CV, Dutton AJ, Vaughan JA. (1994). The toxicity of three second-generation rodenticides to Barn Owls. Pestic Sci. 42(3), 179-184. doi: https://doi.org/10.1002/ ps.2780420307.

Greaves J, Rennison B. (1973). Population aspects of warfarin resistance in the brown rat, Rattus norvegicus. Mammal Review. 3(2), 27-29. doi: https://doi.org/10.1111/j.1365-2907.1973. tb00166.x.

Griggs AN, Allbaugh RA, Tofflemire KL, Ben-Shlomo G, Whitley D, Paulsen ME. (2016). Anticoagulant rodenticide toxicity in six dogs presenting for ocular disease. Vet Ophthalmol. 19(1), 73-80. doi: https://doi.org/10.1111/vop.12267.

Gupta RC. (2018). Non-anticoagulant rodenticides. Gupta R. eds. Veterinary Toxicology. Elsevier Inc. p. 613-626.

Hayes WJ. (1950). Control of Norway rats with residual rodenticide warfarin. Public Health Rep. 65(47), 1537-1555.

Hughes J, Sharp E, Taylor M, Melton L, Hartley G. (2013). Monitoring agricultural rodenticide use and secondary exposure of raptors in Scotland. Ecotoxicology. 22(6), 974-984. doi: https://doi.org/10.1007/s10646-013-1074-9.

Huntington S, Fenik Y, Vohra R, Geller RJ. (2016). Human bromethalin exposures reported to a US statewide poison contro system. Clin Toxicol. 54(3), 277-281. doi: https://doi.org/10.3 109/15563650.2016.1139713.

Johnston JJ, Pitt WC, Sugihara RT, Eisemann JD, Primus TM, Holmes MJ, Crocker J, Hart A. (2005). Probabilistic risk assessment for snails, slugs, and endangered honeycreepers in diphacinone rodenticide baited areas on Hawaii, USA. Environ Toxicol Chem. 24(6), 1557-1567. doi: https://doi.org/10.1897/04-255R.1. 
Kammerer M, Pouliquen H, Pinault L, Loyau M. (1998). Residues depletion in egg after warfarin ingestion by laying hens. Vet Hum Toxicol. 40(5), 273-275.

Kaukeinen DE, Buckle AP. (1992). Evaluations of aversive agents to increase the selectivity of rodenticides, with emphasis on denatonium benzoate (Bitrex ${ }^{\circledR}$ ) bittering agent. Proceedings of the Fifteenth Vertebrate Pest Conference, March 3-5, California-USA.

King N, Tran M-H. (2015). Long-acting anticoagulant rodenticide (superwarfarin) poisoning: a review of its historical development, epidemiology, and clinical management. Transfus Med Rev. 29(4), 250-258. doi: https://doi.org/10.1016/j. tmrv.2015.06.002.

Kırbaş A, Özkanlar Y, Özkanlar S, Aktaş M. (2012). Bir köpekte şiddetli burun kanaması ile seyreden varfarin toksikasyonu. Ataturk Univ Vet Bilim Derg. 7(3), 201-209.

Kondolot M, Akyıldız B, Görözen F, Kurtoğlu S, Patıroğlu T. (2009). Çocuk acil servisine getirilen zehirlenme olgularının değerlendirilmesi. Cocuk Sagligi ve Hastaliklari Derg. 52(2), 68-64.

Kopanke JH, Horak KE, Musselman E, Miller CA, Bennett K, Olver CS, Volker SF, VandeWoude S, Bevins SN. (2018). Effects of low-level brodifacoum exposure on the feline immune response. Sci Rep. 8(1), 1-13. doi: https://doi.org/10.1038/ s41598-018-26558-3.

Lefebvre Sb, Fourel I, Queffélec S, Vodovar D, Megarbane B, Benoit E, Siguret V, Lattard V. (2017). Poisoning by anticoagulant rodenticides in humans and animals: causes and consequences. IntechOpen, p. 11-32. doi: http://dx.doi.org/10.5772/ intechopen.69955.

Lohr MT. (2018). Anticoagulant rodenticide exposure in an Australian predatory bird increases with proximity to developed habitat. Sci Total Environ. 643, 134-144. doi: https://doi.org/10.1016/j.scitotenv.2018.06.207.

López-Perea JJ, Camarero PR, Molina-López RA, Parpal L, Obón E, Solá J, Mateo R. (2015). Interspecific and geographical differences in anticoagulant rodenticide residues of predatory wildlife from the Mediterranean region of Spain. Sci Total Environ. 511, 259-267. doi: https://doi.org/10.1016/j.scitotenv.2014.12.042.

López-Perea JJ, Camarero PR, Sánchez-Barbudo IS, Mateo R. (2019). Urbanization and cattle density are determinants in the exposure to anticoagulant rodenticides of non-target wildlife. Environ Pollut. 244, 801-808. doi: https://doi.org/10.1016/j.envpol.2018.10.101.

Lund M. (1984). Resistance to the second-generation anticoagulant rodenticides. Proceedings of the Eleventh Vertebrate Pest Conference, March 6-8, California-USA.

Ma M, Zhang M, Tang X, Li Z. (2017). Massive neonatal intracranial hemorrhage caused by bromadiolone: A case report. Medicine. 96(45). doi: https://dx.doi.org/10.1097\%2FMD.0000000000008506

Macdonald D, Fenn M, Gelling M. (2015). The natural history of rodents: preadaptations to pestilence. Buckle A, Smith R. eds Rodent pests and their control. CAB International, United Kingdom. p. 1-18.

Martin A, Steed LC, Redfern R, Gill J, Huson L. (1979). Warfarin-resistance genotype determination in the Norway rat, Rattus norvegicus. Lab Anim. 13(3), 209-214. doi: https://doi.org/10.1258\%2F002367779780937852.

Martínez-Padilla J, López-Idiáquez D, López-Perea JJ, Mateo R, Paz A, Viñuela J. (2017). A negative association between bromadiolone exposure and nestling body condition in common kestrels: management implications for vole outbreaks.
Pest Manag Sci. 73(2), 364-370. doi: https://doi.org/10.1002/ ps.4435.

Mooney J, Lynch MR, Prescott CV, Clegg T, Loughlin M, Hannon B, Moore C, Faulkner R. (2018). VKORC1 sequence variants associated with resistance to anticoagulant rodenticides in Irish populations of Rattus norvegicus and Mus musculus domesticus. Sci Rep. 8(1), 4535. doi: https://doi.org/10.1038/ s41598-018-22815-7

Morgan AM. (2006). Teratogenic effect of the coumarinic anticoagulant rodenticide, racumin in white rats. $J$ Egypt Soc Toxicol. 34, 5-14.

Murphy MJ. (2018). Anticoagulant rodenticides Gupta R. eds. Veterinary Toxicology. Elsevier Inc. p. 583-612.

Murray M. (2011). Anticoagulant rodenticide exposure and toxicosis in four species of birds of prey presented to a wildlife clinic in Massachusetts, 2006-2010. J Zoo Wildl Med. 42(1), 88-97. doi: https://doi.org/10.1638/2010-0188.1.

Newton I, Wyllie I, Gray A, Eadsforth CV. (1994). The toxicity of the rodenticide flocoumafen to barn owls and its elimination via pellets. Pestic Sci. 41(3), 187-193. doi: https://doi. org/10.1002/ps.2780410304.

Ng WY, Ching CK, Chong YK, Ng SW, Cheung WL, Mak TWL. (2018). Retrospective study of the characteristics of anticoagulant-type rodenticide poisoning in Hong Kong. J Med Toxicol. 14(3), 212-228. doi: https://doi.org/10.1007/s13181018-0660-x.

Ozturk Z, Ugras K. (2018). Pregnancy outcomes after suicide attempts by self-poisoning and drug overdose: experience of a clinical pharmacology consultation service in Izmir, Turkey. $J$ Obstet Gynaecol, 38(7), 1026-1028. doi: https://doi.org/10.10 80/01443615.2017.1419463.

Özdemir ZN, Şahin U, Merter $M$, Gündüz $M$, Ateşağaoğlu $B$, Beksaç M. (2016). A case of superwarfarin poisoning due to repetitive occupational dermal rodenticide exposure in a worker. Turk J Hematol. 33(3), 251-253. doi: https://dx.doi.org/10.4274\%2Ftjh.2015.0433.

Pitt WC, Higashi M, Primus TM. (2011). The effect of cooking on diphacinone residues related to human consumption of feral pig tissues. Food Chem Toxicol. 49(9), 2030-2034. doi: https:// doi.org/10.1016/j.fct.2011.05.014.

Poessel SA, Breck SW, Fox KA, Gese EM. (2015). Anticoagulant rodenticide exposure and toxicosis in coyotes (Canis latrans) in the Denver metropolitan area. J Wildl Dis. 51(1), 265-268. doi: https://doi.org/10.7589/2014-04-116.

Prat-Mairet Y, Fourel I, Barrat J, Sage M, Giraudoux P, Coeurdassier M. (2017). Non-invasive monitoring of red fox exposure to rodenticides from scats. Ecol Indic. 72, 777-783. doi: https:// doi.org/10.1016/j.ecolind.2016.08.058.

Proulx G, Mackenzie N. (2012). Relative abundance of American badger (Taxidea taxus) and red fox (Vulpes vulpes) in landscapes with high and low rodenticide poisoning levels. Integr Zool. 7(1), 41-47. doi: https://doi.org/10.1111/j.17494877.2011.00276.x.

Rahman NA, Das S, Chaudhari VA, Nandagopal S, Badhe B. (2017). Blending of rodenticide and battery acid-a rare and fatal suicide mix. Egypt J Forensic Sci. 7, 1-5. doi: 10.1186/ s41935-017-0002-1

Rattner BA, Lazarus RS, Elliott JE, Shore RF, van den Brink N. (2014). Adverse outcome pathway and risks of anticoagulant rodenticides to predatory wildlife. Environ Sci Technol. 48(15), 8433-8445. doi: https://doi.org/10.1021/es501740n.

Rennison BD, Dubock A. (1978). Field trials of WBA 8119 (PP 581 brodifacoum*) against warfarin-resistant infestations of Rat- 
tus norvegicus. Epidemiol Infect. 80(1), 77-82. doi: https://doi. org/10.1017/S0022172400053419.

Riley SP, Bromley C, Poppenga RH, Uzal FA, Whited L, Sauvajot RM. (2007). Anticoagulant exposure and notoedric mange in bobcats and mountain lions in urban southern California. J Wildl Manag. 71(6), 1874-1884. doi: https://doi. org/10.2193/2005-615.

Ruiz-Suárez N, Henríquez-Hernández LA, Valerón PF, Boada LD, Zumbado M, Camacho M, Almeida-González M, Luzardo OP. (2014). Assessment of anticoagulant rodenticide exposure in six raptor species from the Canary Islands (Spain). Sci Total Environ. 485, 371-376. doi: https://doi.org/10.1016/j.scitotenv.2014.03.094.

Sainsbury KA, Shore RF, Schofield H, Croose E, Pereira MG, Sleep D, Kitchener AC, Hantke G, McDonald RA. (2018). Long-term increase in secondary exposure to anticoagulant rodenticides in European polecats Mustela putorius in Great Britain. Environ Pollut. 236, 689-698. doi: https://doi.org/10.1016/j. envpol.2018.02.004.

Salim H, Noor HM, Hamid NH, Omar D, Kasim A, Abdin C. (2015). The effects of rodenticide residues deposited in eggs of Tyto alba to eggshell thickness. Sains Malays. 44, 559-564.

Sánchez-Barbudo IS, Camarero PR, Mateo R. (2012). Primary and secondary poisoning by anticoagulant rodenticides of non-target animals in Spain. Sci Total Environ. 420, 280-288. doi: https://doi.org/10.1016/j.scitotenv.2012.01.028.

Sarabia J, Sánchez-Barbudo I, Siqueira W, Mateo R, Rollán E, Pizarro M. (2008). Lesions associated with the plexus venosus subcutaneus collaris of pigeons with chlorophacinone toxicosis. Avian Dis. 52(3), 540-543. doi: https://doi.or$\mathrm{g} / 10.1637 / 8251-020508-C a s e .1$.

Saravanan K, Kanakasabai R. (2004). Evaluation of secondary poisoning of difethialone, a new second-generation anticoagulant rodenticide to Barn owl, Tyto alba Hartert under captivity. Indian J Exp Biol. 42, 1013-1016.

Seljetun KO, Eliassen E, Karinen R, Moe L, Vindenes V. (2018). Quantitative method for analysis of six anticoagulant rodenticides in faeces, applied in a case with repeated samples from a dog. Acta Vet Scand. 60(1), 3. doi: https://doi.org/10.1186/ s13028-018-0357-9.

Seljetun KO, Sandvik M, Vindenes V, Eliassen E, Øiestad EL, Madslien K, Moe L. (2020). Comparison of anticoagulant rodenticide concentrations in liver and feces from apparently healthy red foxes. J Vet Diagn Invest. 32(4), 560-564. doi: https://doi. org/10.1177\%2F1040638720927365.

Shepherd G, Klein-Schwartz W, Anderson BD. (2002). Acute, unintentional pediatric brodifacoum ingestions. Pediatr Emerg Care. 18(3), 174-178.

Shore RF, Birks JD, Freestone P. (1999). Exposure of non-target vertebrates to second-generation rodenticides in Britain, with particular reference to the polecat Mustela putorius. $N Z$ J Ecol. 23(2), 199-206.
Smith R, Shore R. (2015). Environmental Impacts of Rodenticides. Buckle A, Smith R. eds. Rodent pests and their control. CAB International, United Kingdom. p. 330-345.

Spurr E, Drew K. (1999). Invertebrates feeding on baits used for vertebrate pest control in New Zealand. N Z J Ecol. 23(2), 167173.

Stansley W, Cummings M, Vudathala D, Murphy LA. (2014). Anticoagulant rodenticides in red-tailed hawks, Buteo jamaicensis, and great horned owls, Bubo virginianus, from New Jersey, USA, 2008-2010. Bull Environ Contam Toxicol. 92(1), 6-9. doi: https://doi.org/10.1007/s00128-013-1135-z.

Stone WB, Okoniewski JC, Stedelin JR. (1999). Poisoning of wildlife with anticoagulant rodenticides in New York. J Wildl Dis. 35(2), 187-193. doi: https://doi.org/10.7589/0090-355835.2.187.

Svendsen S, Kolstad HA, Steesby E. (2002). Bleeding problems associated with occupational exposure to anticoagulant rodenticides. Int Arch Occup Environ Health. 75(7), 515-517. doi: https://doi.org/10.1007/s00420-002-0339-z.

Thomer AJ, Santoro KB. (2018). Anticoagulant rodenticide toxicosis causing tracheal collapse in 4 small breed dogs. $J$ Vet Emerg Crit Care (San Antonio). 28(6), 573-578. doi: https:// doi.org/10.1111/vec.12774.

Vries de JX, Schmitz-Kummer E. (1994). Determination of the coumarin anticoagulant phenprocoumon and metabolites in human plasma, urine and breast milk by high-performance liquid chromatography after solid-phase extraction. J Chromatogr B Biomed Sci Appl. 655(1), 63-71. doi: https://doi. org/10.1016/0378-4347(94)00050-6.

Vyas NB. (2017). Rodenticide incidents of exposure and adverse effects on non-raptor birds. Sci Total Environ. 609, 68-76. doi: https://doi.org/10.1016/j.scitotenv.2017.07.004.

Walker J, Beach F. (2002). Deliberate self-poisoning with rodenticide: a diagnostic dilemma. Int J Clin Pract. 56(3), 223-224.

Watt BE, Proudfoot AT, Bradberry SM, Vale JA. (2005). Anticoagulant rodenticides. Toxicol Rev. 24(4), 259-269. doi: https://doi. org/10.2165/00139709-200524040-00005.

Xiang L, Min Z, Alan Z, Yaohui W. (2014). Retrospective study of twenty-four patients with prolonged coagulopathy due to long-acting anti-vitamin $\mathrm{K}$ rodenticide poisoning. $\mathrm{Am} J$ Med Sci. 347(4), 299-304. doi: https://doi.org/10.1097/MAJ. 0b013e318291cb7d.

Yu H-Y, Lin J-L, Fu J-F, Lin J-H, Liu S-H, Weng C-H, Huang W-H, Chen K-H, Hsu C-W, Yen T-H. (2013). Outcomes of patients with rodenticide poisoning at a far east poison center. SpringerPlus. 2(1), 505. doi: https://doi.org/10.1186/2193-1801-2505.

Zielinski WJ, Linnell MA, Schwartz MK, Pilgrim K. (2020). Exploiting the winter trophic relationship between weasels (Mustela spp.) and their microtine prey as a survey method for weasels in meadow ecosystems. Northwest Sci. 93(3-4), 185-192. doi: https://doi.org/10.3955/046.093.0303 